\title{
Théophile Gautier et la religion de l'art, sous la direction de Martine LAVAUD et Paolo TORTONESE
}

\section{Patrick Berthier}

\section{(2) OpenEdition}

\section{Journals}

\section{Édition électronique}

URL : http://journals.openedition.org/studifrancesi/15626

DOI : $10.4000 /$ studifrancesi. 15626

ISSN : 2427-5856

\section{Éditeur}

Rosenberg \& Sellier

\section{Édition imprimée}

Date de publication : 1 décembre 2018

Pagination : 513-514

ISSN : 0039-2944

\section{Référence électronique}

Patrick Berthier, "Théophile Gautier et la religion de l'art, sous la direction de Martine Lavaud et Paolo TORTONESE », Studi Francesi [En ligne], 186 (LXII | III) | 2018, mis en ligne le 01 janvier 2019, consulté le 06 janvier 2021. URL : http://journals.openedition.org/studifrancesi/15626 ; DOI : https://doi.org/ 10.4000/studifrancesi.15626

Ce document a été généré automatiquement le 6 janvier 2021.

\section{(c) (†) $\$$}

Studi Francesi è distribuita con Licenza Creative Commons Attribuzione - Non commerciale - Non opere derivate 4.0 Internazionale. 


\title{
Théophile Gautier et la religion de l'art, sous la direction de Martine LAVAUD et Paolo TORTONESE
}

\author{
Patrick Berthier
}

\section{RÉFÉRENCE}

Théophile Gautier et la religion de l'art, sous la direction de Martine LAVAUD et Paolo TORTONESE, Paris, Classiques Garnier, 2018, 254 pp.

1 Le bicentenaire de la naissance de Théophile Gautier a été célébré par plusieurs manifestations et colloques dont voici le dernier, publié très en retard pour des raisons largement imputables à l'éditeur. Nous lisons ici des textes de sept ans d'âge, alors que, depuis, la bibliographie a bien progressé; n'en donnons que l'exemple le plus piquant: Alain Montandon, qui dirige, chez Champion, l'édition des Euvres complètes, renvoie dans son article à la vieille édition Hetzel (catastrophique) des feuilletons dramatiques, alors qu'il supervise la nouvelle et la seule qui soit désormais fiable - mais, en 2011, elle n'en était qu'à son troisième volume (il y en a dix de publiés à la date de rédaction de ce billet). Il aurait idéalement fallu donner aux auteurs la possibilité d'une relecture qui permît de rectifier au moins telles ou telles de leurs références - et aussi d'améliorer la langue ou de gommer quelques bévues un peu voyantes: Meyerbeer n'était pas belge (p. 32) et Les Contemplations ne sont assurément pas de 1841 (p. 78). Même s'agissant d'un objet intemporel [?] comme l'art, ce n'est pas un aspect négligeable des choses.

2 Le thème retenu pour ces deux journées du musée d'Orsay, en mai 2011, est sans doute un des plus délicats qu'on puisse tenter de mettre en lumière; les organisateurs, délaissant pour le titre du volume la formule-cliché de l'art pour l'art, que Gautier luimême utilise peu, ont avec raison placé au centre la notion de culte, de «religion» de l'art, qui fédère de façons très diverses les quatorze articles proposés. On y voit que le mot «art» ne se limite pas aux «beaux-arts» au sens étroit, mais qu'il est possible de 
réfléchir à ce qu'était la beauté pour Gautier à partir d'autres corpus, comme le théâtre, ainsi que le fait Corinne Bayle en utilisant «Shakespeare aux Funambules», article de 1842 sur la pantomime, et «Le théâtre à Munich», série de cinq feuilletons de 1854 sur Lessing, Schiller, Goethe. On peut aussi tenter de comprendre le regard de Gautier en partant de ce qui est pour lui la laideur: la Vénus hottentote dans la réalité, ou en art les Baigneuses de Courbet (deux exemples étudiés par Christopher Bains), ou en repensant son usage du mot et de la notion de «barbare», sujet de l'article de Barbara Bohac, et thème privilégié de l'exposé conclusif de Paolo Tortonese largement consacré à l'article capital de 1847 «Du Beau dans l'art» (la majuscule à «Beau» est de Gautier).

3 L'éventail des contributions va des points de vue les plus resserrés aux plus larges tentatives de bilan. Du côté des regards ciblés, on pensera à l'étude, par Pierre Georgel, des textes de Gautier sur Hugo dessinateur, ou à celle, très savante et un peu submergée par la surabondance des notes, de l'hellénisme d'Émaux et Camées par Myriam Robic. Du côté des réflexions d'ensemble, on trouve l'article ambitieux de Wolfgang Drost sur l'esthétique de Gautier, aboutissant à l'idée que Gautier est moins un parnassien qu'un pré-décadent, ou celui de Marie-Hélène Girard qui s'attache de belle façon au thème de «l'éternité de l'art», symbolisé par l'Apothéose d'Homère d'Ingres, peintre aimé de Gautier car il incarne une «conception vivante et opératoire de la tradition» (p. 119). Chacun a trouvé son angle d'approche: le «bel objet» pour Anne Geisler-Szmulewicz, qui s'appuie sur l'admiration de Gautier pour Ziegler le céramiste, ou pour FromentMeurice l'orfèvre; le vocabulaire pour Alain Montandon, qui passe en revue de façon suggestive les occurrences de l'adjectif «admirable» chez le critique; tels textes aimés pour Martine Lavaud, qui relit (et relie) avec brio Le Roi Candaule et Arria Marcella, deux nouvelles du regard et de la frustration. Même des études qu'on pourrait d'abord croire éloignées du thème de l'ouvrage, comme celle de Thierry Roger sur la «liturgie funèbre» du recueil La Comédie de la Mort, viennent in fine confirmer l'insuffisance désormais avérée du cliché de «l'art pourt l'art» (qui n'en a pas moins la vie dure), et l'extrême complexité de ce culte indéfiniment diversifié de Gautier pour un art luimême si divers: Marie-Claude Schapira, fine connaisseuse de l'œuvre narrative, qui se demande si Gautier prosateur est un «dévôt» de l'art, ou encore Cassandra Hamrick, qui étudie son art d'《être un autre» dans sa critique d'art, apportent elles aussi des éléments à cette réflexion dont la nature même est d'être in progress.

On ne sort pas, en effet, de la lecture de ce petit volume avec des idées définitives, et c'est heureux; plutôt avec des raisons nouvelles de relire le Gautier qu'on connaît, et peut-être surtout de découvrir celui qu'on ne connaît pas - ces trésors, peu à peu révélés par l'édition des đuvres complètes, de l'immense corpus journalistique, qui est bel et bien une cuvre au même titre que la prose ou la poésie, et qui pose un si riche regard sur le siècle comme sur le passé. 